\title{
PERCEPÇÕES DE BRASILEIROS ACERCA DO PROCESSO DE ADAPTAÇÃO CULTURAL AO JAPÃO
}

\author{
Brazilians' perceptions regarding the cultural adaptation process \\ in Japan
}

\author{
Jesselyn Nayara Tashima* \\ Cláudio Vaz Torres*
}

\begin{abstract}
Resumo. Esta pesquisa objetivou investigar as formas de aculturação dos brasileiros ao Japão e as variáveis que auxiliam na compreensão da adaptação cultural. Foram realizadas entrevistas com 15 imigrantes brasileiros residentes no Japão. Os resultados indicaram uma separação social entre brasileiros e japoneses e apontaram para a importância do suporte social e do engajamento na cultura japonesa na adaptação ao país. Concluiu-se com as contribuições teóricas, metodológicas e práticas deste estudo e com a apresentação das limitações e sugestões para pesquisas futuras.
\end{abstract}

Palavras-chave: aculturação; Psicologia Transcultural; imigração; adaptação cultural.

\begin{abstract}
This research aimed to investigate the forms of acculturation of Brazilians to Japan and the variables that help to understand the cultural adaptation. Interviews were conducted with 15 Brazilian immigrants living in Japan. Results indicated a social separation between Brazilians and Japanese and pointed to the importance of social support and engagement in Japanese culture in adapting to the country. It was concluded with the theoretical, methodological and practical contributions of this study and with the presentation of limitations and suggestions for future research.
\end{abstract}

Keywords: acculturation; Cross-Cultural Psychology; immigration; cultural adaptation.

Programa de Pós-Graduação em Psicologia Social, do Trabalho e das Organizações Universidade de Brasília. Brasília, DF, Brasil. 
"O que acontece às pessoas quando elas mudam da cultura na qual nasceram e cresceram para uma cultura nova e desconhecida?"1 . Essa pergunta tem incentivado pesquisadores de diversas disciplinas a investigarem o contato entre indivíduos e grupos de diferentes culturas. Esses encontros interculturais permitem que não somente os indivíduos como também as sociedades envolvidas sejam impulsionados a um processo de mudanças. As mudanças longas e contínuas resultantes do encontro entre grupos ou indivíduos de culturas diferentes é a chamada aculturação². Mais recentemente, esse termo tem sido largamente utilizado pela Psicologia como um fenômeno individual, chamado de aculturação psicológica ${ }^{3}$, referindo-se ao processo fluido e dinâmico em que o indivíduo negocia duas ou mais culturas e que acarreta mudanças de valores, atitudes e comportamentos com o objetivo de se ajustar ao novo contexto.

Grande parte das pesquisas psicológicas sobre aculturação tem sido conduzida pela Psicologia Transcultural. Esse campo teórico tem como objetivo investigar as influências da cultura em diversos processos psicológicos e passou a adotar a aculturação como um dos temas centrais de pesquisa ${ }^{4}$. $\mathrm{O}$ aumento do interesse sobre a temática pelos psicólogos transculturais impulsionou a criação de diversos modelos teóricos de aculturação na tentativa de explicar o fenômeno do contato intercultural.

Um desses modelos existentes é o quadro teórico de Arends-Tóth e Van de $V_{\text {ijver }}^{5}$. De acordo com esse modelo, o processo de aculturação pode ser melhor compreendido ao dividi-lo em fatores antecedentes, orientações de aculturação e as consequências da aculturação. Os fatores antecedentes são as condições de aculturação e envolvem as variáveis individuais, grupais e contextuais que influenciam esse processo. Em nível contextual, citam-se as características da sociedade anfitriã (por exemplo, políticas migratórias) e as da sociedade de origem (aspectos econômicos e políticos, entre outros). Em nível grupal, destacam-se os atributos dos grupos em interação, como por exemplo o status social do grupo imigrante. Em nível individual, encontram-se as características pessoais e situacionais que interferem no processo de aculturação, tais como as variáveis sociodemográficas, motivação ${ }^{6}$, fatores de personalidade, empatia cultural, autoeficácia transcultural, tempo de residência, conhecimento cultural,

\footnotetext{
SAM, David, BERRY, John. Acculturation: When Individuals and Groups of Different Cultural Backgrounds Meet, p. 472.

2 REDFIELD, Robert, LINTON, Ralph, HERSKOVITS, Melville. Memorandum for the study of acculturation.

3 SAM, David, BERRY, John. The Cambridge Handbook of Acculturation Psychology.

4 Ibidem.

5 ARENDS-TÓTH, Judit, VAN DE VIJVER, Fons. Issues in the conceptualization and assessment of acculturation.

6 BERRY, John. Immigration, acculturation and adaptation.
} 
experiência intercultural anterior, percepção de distância cultural, domínio do idioma, contato com os anfitriões ${ }^{7}$, expectativas ${ }^{8}$, estresse percebido, percepção de suporte social, estratégias de enfrentamento ${ }^{9}$ e discriminação percebida ${ }^{10}$.

O segundo componente do modelo de Arends-Tóth e Van de Vijver são as orientações ou estratégias de aculturação que dizem respeito à manutenção ou não de características importantes da cultura original e ao contato e participação ou não em atividades da cultura anfitriã ${ }^{11}$. A partir dessas possibilidades, de manutenção ou adoção de aspectos da cultura original e/ou da cultura anfitriã, quatro estratégias de aculturação podem ser desenvolvidas pelos indivíduos ou grupos migrantes. A primeira, a assimilação, ocorre quando os indivíduos migrantes optam por não manter sua identidade cultural original e escolhem adotar prioritariamente aspectos da cultura anfitriã. A separação acontece quando os indivíduos mantêm a cultura de origem e evitam a incorporação da cultura receptora. Já a integração ocorre quando os indivíduos escolhem manter as características culturais originais como também interagir e participar das atividades da sociedade anfitriã. Por fim, a marginalização se caracteriza pelo pouco interesse em manter a cultura original como pela desvalorização da interação com a cultura hospedeira. A literatura tem sido consistente em apontar a integração ou biculturalismo como a estratégia mais adequada para o contexto da aculturação já que produz mais benefícios em todas as áreas da vida ${ }^{12}$.

O último componente do modelo é a adaptação cultural que se refere às consequências ou resultados da aculturação ${ }^{13}$. Essa variável pode ser definida como as mudanças relativamente estáveis que acontecem nos indivíduos ou grupos migrantes como respostas às novas exigências contextuais ${ }^{14}$. A adaptação cultural pode ser diferenciada em adaptação psicológica e adaptação sociocultural ${ }^{15}$. A adaptação psicológica inclui as consequências emocionais e afetivas advindas deste processo de aculturação. Já a adaptação sociocultural abrange as competências e conhecimentos necessários para lidar com os aspectos mais práticos da nova sociedade.

WILSON, Jessie, WARD, Colleen, FISCHER, Ronald. Beyond culture learning theory: What can personality tell us about cultural competence?

8 MÄHÖNEN, Tuuli Anna, JASINSKAJA-LAHTI, Inga. Acculturation expectations and experiences as predictors of ethnic migrants' psychological well-being.

9 KUO, Ben, KWANTES, Catherine. Testing predictive models of positive and negative affect with psychosocial, acculturation, and coping variables in a multiethnic undergraduate sample.

${ }^{10}$ MUSSO, Pasquale, INGUGLIAA, Cristiano, LO COCO, Alida. Acculturation Profiles and Perceived Discrimination: Associations with Psychosocial Well-being Among Tunisian Adolescents in Italy.

11 BERRY, op. cit.

${ }^{12}$ NGUYEN, Angela-Minhtu, BENET-MARTÍNEZ, Verónica. Biculturalism and adjustment: A metaanalysis.

13 ARENDS-TÓTH, VAN DE VIJVER, op. cit.

14 SAM, BERRY, op. cit.

15 SEARLE, Wendy, WARD, Colleen. The prediction of psychological and socio-cultural adjustment during cross-cultural transitions. 
Grande parte desse panorama teórico da Psicologia Transcultural sobre aculturação tem sido resultado de pesquisas sobre os encontros interculturais que ocorrem em países da Europa e dos Estados Unidos e poucos estudos têm envolvido a população brasileira, em especial, a comunidade brasileira no Japão. Por outro lado, os estudos sobre os brasileiros residentes no Japão têm sido conduzidos mais pelos teóricos da Educação, Sociologia, Antropologia, Geografia, História e Administração e menos pelos pesquisadores da Psicologia ${ }^{16}$.

Atualmente, existem cerca de 173.437 brasileiros residentes no Japão ${ }^{17}$. É o quarto grupo imigrante mais numeroso no país e representa um grupo com experiência peculiar se comparada aos vários movimentos migratórios recentes. Apesar de a maioria dos brasileiros residentes nesse país compartilharem uma herança cultural com seus anfitriões, a chegada ao país de seus antepassados evidencia uma significativa separação social entre japoneses e decasséguis brasileiros ${ }^{18}$. Além dessa separação entre brasileiros e japoneses, vários estudos têm sugerido a existência de inúmeras dificuldades no processo de adaptação dos brasileiros ao Japão que frequentemente têm lhes causado grandes prejuízos psicológicos e sociais. A literatura sobre a comunidade brasileira no Japão tem apontado que essas dificuldades estão mais frequentemente relacionadas à falta de domínio com o idioma, rotina exaustiva decorrente do tipo de trabalho que é mais usualmente oferecido aos brasileiros (trabalhos em fábricas) ${ }^{19}$, grandes diferenças culturais entre Japão e Brasi ${ }^{20}$, conflitos de identidade cultural ${ }^{21} \mathrm{e}$ conflitos intergrupais, como relatos de preconceito e discriminação ${ }^{22}$.

A escassez de estudos pela Psicologia envolvendo esta população, apesar do número expressivo de brasileiros neste país e do forte impacto econômico, social e psicológico que esta imigração tem causado aos brasileiros e japoneses, pode limitar tanto o avanço da literatura de aculturação bem como a construção de políticas públicas mais adequadas a esse grupo. Esta pesquisa é uma resposta a essa lacuna de conhecimentos envolvendo a população brasileira no Japão sob o olhar da Psicologia, mais especificadamente da Psicologia Transcultural, cujos resultados e conhecimentos podem possibilitar uma compreensão mais profunda do processo de aculturação deste grupo e assim, favorecer discussões teóricas e políticas com o objetivo de favorecer a área e esta população.

\footnotetext{
${ }^{16}$ YANO, Luciane Patrícia. Famílias brasileiras no Japão: migração transnacional, adaptação e estresse aculturativo.

17 JAPAN STATISTICAL YEARBOOK 2017. Statistics Bureau.

18 TSUDA, Takeyuki. Migration and Alienation: Japanese-Brazilian Return Migrants and the Search for Homeland Abroad.

${ }^{19}$ RESSTEL, Cizina Célia Fernandes Pereira. Desamparo psíquico nos filhos de Dekasseguis no retorno ao Brasil.

${ }^{20}$ SUGUIURA, Marcos Hiroyuki. Relações entre a rede social e as migrações Brasil-Japão.

${ }^{21}$ ISHIKAWA, Eunice Akemi. A identidade étnica dos jovens brasileiros no Japão.

22 YANO, op. cit.
} 
Diante do exposto, faz-se necessário responder à pergunta: Como é o processo de aculturação dos brasileiros no Japão? Quais variáveis contribuem para a compreensão da adaptação cultural neste contexto? Este estudo, que tem como objetivo geral compreender o processo de aculturação dos brasileiros ao Japão, em termos específicos, visa 1) investigar as formas de aculturação dos brasileiros ao Japão e 2) explorar as variáveis psicológicas que auxiliam na compreensão da adaptação cultural.

\section{Método e participantes}

Para melhor alcance dos resultados, tendo em vista o caráter explorarório deste estudo, foi conduzido um estudo qualitativo e com a finalidade de possibilitar aprofundamento dos fenômenos estudados, a técnica de coleta de dados escolhida foi a entrevista.

A seleção dos participantes foi por conveniência e a amostra resultou em 15 imigrantes brasileiros residentes no Japão, sendo 6 mulheres e 9 homens, dos quais 7 eram decasséguis (descendentes de japoneses e cônjuges com estadia de longa permanência) e 8 sojourners (imigrantes com estadia temporária; como exemplo incluem-se os estudantes internacionais e executivos expatriados). O número de participantes seguiu o critério de saturação ${ }^{23}$, ou seja, as entrevistas foram encerradas no momento em que começaram a fornecer conteúdo repetitivo e não acrescentaram informações novas e relevantes para o estudo, tendo em vista seu caráter exploratório. A média de idade dos participantes foi de 31 anos ( $D P=8,72$ ) e com relação ao tempo de estadia, os decasséguis estão em média há 12,7 anos $(D P=10,53)$ no Japão e os sojourners há 2,9 anos $(D P=3,65)$. Cinco dos sete participantes decasséguis são operários de fábrica e oito dos nove sojouners são estudantes (graduação ou pós-graduação) ou professores universitários. Apenas um entrevistado relatou morar sozinho, todos os outros residem com familiares ou amigos.

\section{Instrumento}

O instrumento utilizado neste estudo foi um roteiro de entrevista semiestruturado construído a partir da literatura de aculturação para a compreensão do fenômeno estudado contendo dez questões-estímulos com o objetivo de investigar categorias e objetivos pré-definidos, conforme apresentados na Tabela 1.

\footnotetext{
${ }^{23}$ BARDIN, Laurence. Análise de Conteúdo.
} 


\section{Tabela 1 - Resumo das Categorias e Objetivos pré-definidos}

\begin{tabular}{ll}
\hline CATEGORIAS OBJETIVOS \\
\hline Gerais
\end{tabular}

Gerais

1. Vida no Brasil

2. Definição de adaptação cultural

3. Motivação, expectativas, experiências e opiniões prévias sobre o Japão

4. Relação com o Japão e os japoneses

5. Relação com o Brasil e os brasileiros

6. Vida atual

7. Percepção de futuro

Específicas

8. Dificuldades vivenciadas

9. Aspectos Facilitadores

10. Estratégias de Enfrentamento
Explorar a rotina, moradia, atividades e aspectos gerais da vida antes da ida ao Japão.

Investigar o que o entrevistado entende por se adaptar a um país diferente.

Conhecer a opinião e experiências com o Japão antes da ida ao país, as motivações e expectativas sobre a nova vida no Japão.

Explorar a visão geral do entrevistado sobre o Japão e os japoneses.

Investigar a opinião do entrevistado sobre o Brasil e os brasileiros.

Pesquisar a rotina, atividades que exerce, condições de moradia, saúde física e mental, visão da vida no geral.

Conhecer os planos para o futuro pessoal e profissional.

Identificar as principais dificuldades enfrentadas na adaptação ao país.

Explorar os fatores que facilitam ou facilitaram a adaptação ao Japão.

Identificar as formas de enfrentamento das dificuldades da adaptação ao Japão.

\section{Procedimentos de coleta de dados}

Os participantes foram recrutados pelo método de bola de neve em redes sociais. O primeiro contato foi feito através de e-mails ou mensagens por redes sociais, em que o convite para a participação na pesquisa era acompanhado da exposição dos objetivos do estudo e da forma de participação do entrevistado. Após o consentimento do Termo de Consentimento Livre e Esclarecido (TCLE) e autorização da gravação, dava-se início à entrevista. Todas as entrevistas foram realizadas por videoconferência por meio do programa Skype uma vez que os entrevistadores se encontravam no Brasil e os entrevistados, no Japão. Para a realização das entrevistas contou-se com seis auxiliares de entrevista. Esses eram estudantes de graduação em Psicologia que receberam treinamento específico pela pesquisadora responsável para a realização das entrevistas e que foram familiarizados com os objetivos e com a temática da pesquisa. Todas as entrevistas foram transcritas manualmente utilizando-se os áudios gravados. As entrevistas foram realizadas individualmente entre abril e junho de 2015 e o tempo médio de duração das entrevistas foi de 45 minutos. 


\section{Procedimento de análise dos dados}

O conteúdo das entrevistas foi analisado pela técnica de análise de conteúdo categorial temática ${ }^{24}$ com 10 categorias pré-definidas e correspondentes às questões-estímulos. Neste estudo, buscou-se seguir as etapas da análise de conteúdo conforme proposto por Bardin: pré-análise, codificação e tratamento dos resultados, inferência e interpretação. Inicialmente, os conteúdos das entrevistas foram explorados através de uma leitura flutuante do material. Foi realizada uma análise semântica das verbalizações e foram atribuídos temas a cada uma delas. A unidade de análise utilizada foram os temas, que após identificados foram agrupados nas categorias pela semelhança no conteúdo. Este estudo adotou o critério de ausência/presença como regra de enumeração já que considerou o conhecimento teórico prévio para a interpretação dos significados presentes no material selecionado.

Com o objetivo de conferir fidedignidade e validade na análise de conteúdo realizada, buscou-se atender aos critérios de exaustividade, representatividade, homogeneidade, pertinência e exclusividade ${ }^{25}$. Além do atendimento desses critérios, cada entrevista foi analisada por dois juízes independentes, a pesquisadora responsável por este estudo e um estudante de doutorado em Psicologia Social com experiência e conhecimento na técnica de análise de conteúdo, com o objetivo de diminuir o viés do pesquisador e acrescentar validade e fidedignidade aos resultados encontrados. A tarefa de cada juiz consistia em agrupar os temas em categorias que eles julgavam pertinentes. Dessa maneira, a análise de um juiz era comparada com a análise do outro juiz para verificar a concordância de respostas. Foi obtido um total de $91 \%$ de concordância entre os dois juízes. O próximo passo consistiu em reavaliar as discordâncias entre os juízes. Considerou-se pertinentes os apontamentos do segundo juiz e, dessa forma, as sugestões propostas foram acatadas e concluiu-se que não havia necessidade de uma nova análise para os dados não congruentes.

\section{Resultados}

Nesta seção, serão relatados os resultados da análise de conteúdo das entrevistas realizadas com as descrições de cada categoria, os temas mais frequentes e alguns exemplos de verbalizações. Os resultados serão apresentados em categorias gerais que se referem ao Objetivo Específico 1, investigar as formas de aculturação dos brasileiros ao Japão, e, em categorias específicas, que estão diretamente relacionadas ao Objetivo Específico 2, que tinha por finalidade investigar variáveis que auxiliam na compreensão da adaptação cultural.

\footnotetext{
${ }^{24}$ Ibidem.

${ }^{25}$ Ibidem.
} 


\section{Categorias gerais: Descrição das formas de aculturação dos imigrantes brasileiros ao Japão}

\section{Categoria 1 - Vida no Brasil}

Os dados analisados sugerem a presença dos seguintes temas: 1) rotina, 2) visão da vida no Brasil: ambiguidades e 3) moradia com familiares e amigos. O primeiro tema representa a rotina "corrida", seja de estudante, empregado ou dona de casa dos participantes, sendo que a maioria dividia a rotina de estudos com o trabalho para complementar a renda familiar. $\mathrm{O}$ segundo tema reflete as visões negativas e positivas da vida no Brasil. A percepção de instabilidade financeira e profissional, a violência e a falta de qualidade de vida nas grandes cidades brasileiras foram mencionadas como as principais razões de insatisfação com a vida no Brasil, como se observa no relato: "Eu sempre tava bem estressada com a violência, com a segurança que não era boa. E a falta de dinheiro, muitas vezes. Era bem estressante essa parte, né?". Por outro lado, a vida social e as redes de apoio foram mencionadas como fatores de satisfação. O terceiro tema aponta que a maioria dos participantes morava com a família ou com amigos antes de irem ao Japão.

\section{Categoria 2 - Definição de adaptação cultural}

Esta categoria apresentou dois temas: 1) adaptar é ter inteligência cultural e 2) adaptar é engajar-se na cultura anfitriã. O primeiro representa os relatos dos participantes que descreveram a adaptação em termos de inteligência ou competência cultural, ou seja, em termos de flexibilidade e respeito às diferenças culturais. Já uma outra parcela de participantes definiu a adaptação cultural em termos de engajamento à cultura local, ou seja, através da interação com a cultura do país anfitrião: "A gente tem que se adaptar à cultura deles e não eles se adaptar à nossa".

\section{Categoria 3 - Motivação, expectativas, experiências e opiniões sobre o Japão antes da viagem ao país}

Nesta categoria foram encontrados três temas: 1) pouco conhecimento sobre o Japão, 2) motivações diferentes, relacionadas ao grupo imigrante e 3) expectativas diferentes sobre o Japão: diferenças entre decasséguis e sojourners. $\mathrm{O}$ primeiro tema aborda o pouco conhecimento sobre o Japão pelos participantes. Este país era visto como um país misterioso e de maneira geral, desconhecido: "Não conhecia nada do Japão, nada mesmo". Além disso, antes de irem ao Japão, havia a percepção de um povo frio, fechado e de um país tecnológico. No segundo tema, encontrou-se que a principal razão da ida ao Japão para os decasséguis foi financeira, como se observa no seguinte depoimento: "Meu sonho era juntar um dinheiro pra voltar pro Brasil, pra comprar um apartamento e voltar a estudar, né?". Já no grupo dos sojourners, a principal causa da mudança estava relacionada à 
busca por aprimoramento acadêmico ou profissional. Gostar, admirar o país e a insatisfação com a vida no Brasil também foram citados como motivadores para a mudança nos dois grupos. No que se refere às expectativas, no grupo dos decasséguis, havia a expectativa de encontrar uma realidade parecida com a contada pelos familiares, uma visão mais idealizada e longe da realidade: "A maioria das pessoas que a gente conversa, vem meio que iludidas, né? Porque quando a gente tá no Brasil, a gente vê uma coisa lá, quando a gente chega aqui é outra, né?". Quanto ao grupo do sojourners, a maioria relatou expectativas de encontrar um país tecnológico, organizado e seguro.

\section{Categoria 4 - Relação com o Japão e os japoneses}

Nesta categoria, observa-se a presença de três temas principais: 1) admiração e respeito pela cultura e pelo povo japonês, 2) percepção de um povo frio e 3) separação entre brasileiros e japoneses. No primeiro tema, verifica-se que a admiração está direcionada às tradições japonesas e características gerais do país, como o fato de ser um país organizado, limpo e tecnológico, e se estende ao jeito prestativo, educado e solidário dos japoneses. A visão negativa está mais associada às pessoas, já que percebem os japoneses como frios, "bitolados", com pouca empatia, fechados e muito voltados para a esfera profissional. O terceiro tema expressa a relação entre brasileiros e japoneses em que se observa uma separação entre os dois grupos. O contato com os japoneses se limita aos ambientes profissionais ou acadêmicos, sendo que as amizades com eles são difíceis de acontecerem e quando há relacionamentos, são superficiais. A separação também se verifica pelo pouco envolvimento dos brasileiros nas atividades da sociedade japonesa e no sentimento de não pertencimento ao país, evidenciado a partir do seguinte relato: "Em geral, eu diria que me sinto um pouco como um intruso, porque é um ambiente que não me sinta como se eu faça parte dele, então acho que é isso".

\section{Categoria 5 - Relação com o Brasil e os brasileiros}

Esta categoria apresentou quatro temas: 1) forte presença do Brasil no Japão: o caso dos decasséguis, 2) distanciamento da cultura brasileira: o caso dos sojourners, 3) o vínculo com o Brasil e 4) relação com o Brasil: amor e ódio. O primeiro tema representa o contato frequente da comunidade decasségui com as pessoas, produtos e serviços brasileiros. Já o segundo tema descreve a relação mais distante do grupo dos sojourners com a realidade brasileira no Japão: "O Brasil não se faz presente no meu cotidiano. Praticamente nem idioma". O terceiro tema reflete a forte ligação e interesse de ambos os grupos com as pessoas que estão no Brasil, especialmente familiares e amigos, e com os assuntos relacionados ao país. O quarto tema refere-se à imagem que eles possuem do Brasil, que ora é descrita como positiva, como um país ideal para se morar, livre e mais aberto, e, em outros momentos, de forma negativa, 
associada a sentimento de ódio, raiva, fracasso e vergonha, como verificado no seguinte depoimento: "E aí você olha pra realidade do Brasil, né? Traz um sentimento assim, de revolta, de fracasso".

\section{Categoria 6 - Vida atual}

Nesta categoria foram encontrados dois temas: 1) adaptação psicológica: ambiguidade de sentimentos e 2) adaptação sociocultural. O primeiro tema reflete a percepção dos participantes acerca da saúde física e mental, satisfação com a vida e conforto psicológico no novo ambiente. Neste tema, verificou-se que, no geral, a amostra de decasséguis se mostra um pouco mais insatisfeita com a vida no Japão do que a de sojourners, expressando inseguranças e arrependimentos: "A gente tá vivendo aqui, sei lá, sobrevivendo na verdade, né?". Já a amostra de sojourners, expressou-se mais satisfeita com a experiência por realizarem atividades que gostam. A maior parte dos entrevistados relatou sentir falta da vida social que tinha no Brasil e afirma que o seu lugar não é no Japão. Quanto ao segundo tema, a adaptação sociocultural, verificou-se que a maioria dos entrevistados apresenta boas habilidades para gerenciar questões de moradia, transporte, lazer e aspectos mais práticos do cotidiano: "Eu posso dizer que eu acostumei bem aqui. Aprendi a me virar, assim, o básico, eu sei sair na rua e me virar".

\section{Categoria 7 - Percepção do futuro}

Nesta categoria, destacam-se os seguintes temas: 1) preocupação com o futuro: a visão dos decasséguis e 2) boas perspectivas de futuro: a visão dos sojourners. Novamente, percebe-se uma distinção clara entre os dois grupos no que diz respeito à visão sobre o futuro. O primeiro tema reflete as incertezas e faltas de perspectivas dos decasséguis com relação ao futuro profissional e retorno ao Brasil: "Eu não vou ter o diploma. Eu estou totalmente desinformada sobre as coisas no Brasil e eu não tenho idade pra trabalhar em uma fábrica aí no Brasil, né?". A maioria relatou o desejo de abrir um negócio próprio no Japão ou no Brasil. Já o segundo tema reflete o comprometimento com a profissão e a visão positiva do futuro do grupo dos sojourners. Além disto, esse grupo também apontou planos além da esfera profissional, como dedicar-se mais ao aprendizado do idioma e da cultura japonesa, adquirir novos hábitos, ter filhos e transmitir o que aprendeu no Japão: "Eu pretendo aproveitar bem esse ano. Aproveitar bem a língua, aprender bem as qualidades positivas do povo japonês".

\section{Categorias específicas: Dificuldades, Facilitadores e Estratégias de Enfrentamento}

\section{Categoria 8 - Dificuldades vivenciadas}

Esta categoria representa os aspectos que dificultam a adaptação ao Japão e foram encontradas três subcategorias que dividem as dificuldades em 
individuais, grupais e contextuais. No primeiro subgrupo, destacaram-se os seguintes temas: 1) a falta de domínio do idioma japonês, 2) dificuldades em aceitar ou se ajustar à cultura japonesa e 3) saudades da família. O primeiro tema reflete a principal dificuldade relatada por todos participantes, a questão do idioma: "É um desespero por não falar frequentemente a língua aqui, né?". O segundo tema representa as dificuldades em lidar com o jeito dos japoneses, frequentemente associado à distância emocional e inflexibilidade, como pode ser exemplificado no seguinte relato: "Difícil (lidar com os japoneses). Difícil porque japoneses, eles têm regras, né? E as regras têm que ser feitas. Se você não fizer, tipo, nossa, os japoneses que tavam ali como nossos chefes faziam um escândalo né? Então, foi bem complicado a adaptação". O terceiro tema expressa a saudade da família e representa um dos fatores que os fazem refletir sobre sua permanência ou não no Japão: "Aqui no Japão, longe da família e do Brasil, a gente vê. Eu pelo menos senti na pele que quando eu fiquei doente ou quando tive dificuldade, a gente sente muita falta da família".

Já no que diz respeito às dificuldades advindas de processos grupais, foram encontrados dois temas: 1) percepção de discriminação e 2) rivalidade e desunião entre os brasileiros. A percepção de discriminação dos japoneses para com os estrangeiros foi relatada por ambos os grupos, porém com mais frequência pelos decasséguis, como se verifica no seguinte relato: "Claro que eu já passei assim por algumas situações um pouquinho desagradáveis. Como existem os japoneses que tratam bem, também existem os japoneses, ainda hoje que são, é, como fala, não num digo racista, é uma palavra muito forte, mas que não aceitam muito bem o estrangeiro". Com menos destaque cita-se o tema do conflito intragrupal, que reflete a rivalidade e desunião entre os brasileiros que residem no Japão percebida pelos decasséguis: "Infelizmente aqui no Japão os brasileiros não têm muita união, né? Então, a desunião aqui é grande, grande, bem grande né?".

Com relação aos fatores contextuais, foram encontrados três temas: 1) ritmo intenso de trabalho ou estudo, 2) distância cultural entre Brasil e Japão e 3) dificuldades relacionadas ao cotidiano. O primeiro tema expressa a percepção da maioria dos participantes sobre a rotina pesada de estudo ou trabalho. A relação entre o ritmo pesado e a adaptação ao Japão fica evidente no seguinte relato: "O ritmo que a gente tem é o problema que eu falei pra você. A gente já viu vários suicídios, ou pessoas dando derrame cedo. Em parte, porque não consegue se adaptar". O segundo tema representa a percepção dos participantes sobre as dificuldades em lidar com as grandes diferenças culturais entre o Japão e o Brasil. No geral, os participantes relataram diferenças relacionadas às características culturais, como tradições e valores bem diferentes do Brasil, mas também relataram grandes diferenças referentes a vários comportamentos, como por exemplo o respeito ao silêncio. Por fim, o terceiro tema expõe as dificuldades relacionadas às questões mais práticas do 
cotidiano, como a dificuldade em se adaptar à comida, ao clima, estilos das moradias (percebidas como pequenas). Dentre os aspectos mais práticos, a questão da comida foi a mais citada pelos participantes.

\section{Categoria 9 - Aspectos facilitadores}

Esta categoria representa os fatores que facilitam a adaptação ao país e pode ser dividida em três subcategorias: individuais, grupais e contextuais. $\mathrm{Na}$ primeira subcategoria, os temas mais relevantes foram: 1 ) habilidades no idioma, 2) inteligência cultural e 3) engajamento na cultura anfitriã. No primeiro tema, a maioria relatou que um bom domínio do idioma japonês pode facilitar a adaptação ao país. Os participantes enfatizaram que falar japonês possibilita compreender as situações, a cultura e abre uma série de oportunidades: "A partir do momento que eu comecei a me comunicar melhor com a língua, eu tive mais oportunidades pra entender como as pessoas pensavam, pra ouvir as pessoas à distância. Então acho que essa foi a principal diferença que fez pra mim". O segundo tema, inteligência cultural, expressa a importância atribuída à habilidade em lidar com culturas diferentes, ou seja, o respeito, abertura, flexibilidade e exibição de comportamentos adequados ao novo contexto. Como exemplo, apresenta-se o seguinte relato: "Porque ao mesmo tempo que eu sou brasileira eu sei me comportar como japonesa. Então assim, quando você sabe se comportar como eles, eles te aceitam um pouco melhor". Já o terceiro tema, o engajamento, pode ser entendido como a percepção de que a incorporação de regras, costumes e crenças da cultura japonesa facilita a adaptação ao Japão: "É tentando viver dentro da cultura deles, né? E é o que a gente tem que deixar muito de brasileiro e começar a se adaptar, se você quer viver bem com eles e no país deles".

Na segunda subcategoria, destaca-se o papel do suporte social. Esse tema é descrito pelos participantes como o auxílio de amigos, familiares e da instituição que trabalham ou estudam para o enfrentamento das principais dificuldades. Esse suporte é percebido como um dos fatores mais importantes para a adaptação ao país, sendo que o suporte de amigos e familiares foi mais mencionado do que o suporte social do Japão, dos japoneses ou das instituições. Como exemplo desse tema, cita-se o seguinte relato: "Eu acho que criei amizades boas aqui, acho que isso me ajudou bem a eu me adaptar por aqui".

A terceira subcategoria, variáveis contextuais, também apresenta dois temas: 1) Japão, um país que funciona e 2) facilidade de consumo. O primeiro tema refere-se às particularidades do Japão que facilitam a adaptação, tais como a organização e funcionamento adequado de serviços de transporte, lazer e alimentação oferecidos à população: "A vida aqui, em geral, facilita muito. As coisas aqui funcionam melhor aqui do que no Brasil, o que é mais fácil 
de se adaptar". O segundo tema se relaciona à facilidade em adquirir produtos no Japão pela questão da acessibilidade, tanto em termos de localização como pelo poder de compra.

\section{Categoria 10 - Estratégias de Enfrentamento}

Esta categoria reflete as principais estratégias de enfrentamento das dificuldades adotadas pelos participantes. Pode-se dividi-las em duas subcategorias: estratégias ativas e estratégias coletivistas. A primeira comporta apenas um tema, o engajamento, e a segunda categoria inclui dois temas: 1) busca por suporte social e 2) apelo à religião. O tema engajamento refere-se às respostas de enfrentamento que buscam ativamente por uma solução, seja através da interação, aprendizado ou resolução dos problemas: "“Eu estava aqui e eu não vou ficar preso dentro de casa né? Saía, conhecia, era vários lugares pra ver, andar e eu saía". O segundo grupo de estratégias foi chamado de coletivistas por abranger comportamentos de busca por apoio social ou familiar e comportamentos decorrentes de crenças ou práticas religiosas, ambos considerados estratégias coletivistas $^{26}$. O primeiro tema expressa a busca por suporte social, ou seja, a procura pelo apoio de amigos e familiares para enfrentar as dificuldades, como verificado no seguinte depoimento: "Conversando, né? Com a família, com os amigos, com os outros mestres da igreja pra poder sobreviver à primeira etapa, né?". O segundo tema, o apelo à religião, representa o envolvimento com a religião com o objetivo de refletir sobre a situação e minimizar o sofrimento: "Mas a gente orou muito a Deus, porque é difícil eles aceitarem, né? Então a minha mãe ela sempre orava assim: Deus ensina esse povo a me amar".

Em resumo, os resultados encontrados sugerem diferenças nas formas de aculturação entre os decasséguis e sojourners, especialmente em questões referentes à motivação, expectativa, ao relacionamento com a cultura brasileira, à percepção do futuro e à satisfação com a vida atual. Grande parte dessas diferenças está, em geral, diretamente relacionada às características de cada grupo, como o tipo de imigração (longa ou curta permanência), ocupação no Japão e demais condições socioeconômicas. No entanto, observaram-se poucas diferenças entre os dois grupos no que se refere aos processos básicos da aculturação, como as dificuldades enfrentadas, os facilitadores da adaptação e as estratégias de enfrentamento adotadas. Com relação às estratégias de enfrentamento das dificuldades, verifica-se que grande parte dos entrevistados buscam estilos ativos e socioemocionais para o manejo das dificuldades. Em geral, os dados apontaram para a existência de uma separação entre brasileiros e japoneses, sustentada pelos relatos de não participação e envolvimento com os

${ }^{26} \mathrm{KUO}$, Ben C. H. Collectivism and coping: Current theories, evidence, and measurements of collective coping. 
anfitriões e com a cultura local. Por fim, os resultados deste estudo destacam a necessidade da aproximação com a cultura japonesa e a importância dos vínculos sociais como fatores importantes para uma adaptação bem-sucedida no país.

\section{Discussão}

Um dos objetivos específicos deste estudo era explorar as formas de aculturação dos imigrantes brasileiros ao Japão e os resultados sugerem a existência de algumas diferenças no processo de aculturação entre os dois grupos imigrantes estudados, os decasséguis e os sojourners. Neste estudo, foram encontradas diferenças entre os dois grupos no que diz respeito às motivações, expectativas, ao relacionamento com a cultura brasileira no Japão, opiniões sobre o Brasil, o futuro e a vida atual. Contudo, apesar de serem grupos com características bastante distintas em termos educacionais, sociais e econômicos, apresentaram similaridades em questões centrais do processo de aculturação (dificuldades, facilitadores e estratégias de enfrentamento). Conforme aponta a literatura ${ }^{27}$, embora a aculturação possa ser experienciada de maneiras bastante divergentes pelos grupos migrantes, as questões centrais da aculturação parecem ser comuns a todos eles. Ao incluir ambas as amostras, este estudo possibilitou adicionar validade aos apontamentos da literatura de aculturação e ampliou as visões sobre os processos de aculturação dos brasileiros no Japão ao identificar quais as variáveis psicológicas são percebidas pelos participantes como importantes para a adaptação a esse país.

Sugere-se ainda que os participantes desta pesquisa apresentam boa adaptação psicológica e sociocultural ao Japão. A maioria declarou estar satisfeita com a vida, ter uma boa saúde física e mental. Entretanto, apesar de sugerirem uma boa adaptação psicológica, os relatos da maior parte dos entrevistados decasséguis expressam preocupações, incertezas e inseguranças quanto ao futuro pessoal e profissional. Essa situação pode estar diretamente relacionada às características econômicas e sociais subjacentes a esse grupo. Como exemplo cita-se o fato de que, para grande parte dos decasséguis, o Japão é visto como uma etapa temporária e que o trabalho pesado nas fábricas e a vida de sacrifícios se justificam apenas para fins econômicos e não como possibilidade de realização profissional no Japão ${ }^{28}$. Situação bem diferente é encontrada nos relatos dos sojourners que percebem o futuro de maneira mais otimista já que apresentam certo planejamento ou direcionamento profissional. No que se refere à adaptação sociocultural, aponta-se que mesmo com o domínio limitado do idioma por grande parte dos participantes, esses

\footnotetext{
27 BERRY, op. cit.

${ }^{28}$ SUGUIURA, op. cit.
} 
indicam exibir boas habilidades nas situações cotidianas mais práticas como locomover-se, alimentar-se, adquirir produtos e serviços.

O segundo objetivo específico deste estudo era identificar variáveis que auxiliam na compreensão da adaptação cultural e os resultados sugerem que as seguintes variáveis desempenham um papel importante na adaptação psicológica e sociocultural deste grupo: habilidade no idioma, inteligência cultural, suporte social, percepção de discriminação, percepção de conflito intragrupal, distância cultural, estratégias de aculturação, estratégias de enfrentamento e variáveis contextuais, como fatores econômicos e sociais do país. Dentre as variáveis mencionadas, algumas se destacaram pela frequência com que foram mencionadas pelos participantes, como a questão do idioma, a distância cultural entre Japão e Brasil, o engajamento na cultura japonesa, estratégia de enfrentamento ativo, percepção de discriminação e a questão dos vínculos sociais, em especial, do suporte social. A questão do idioma é frequentemente apontada em outros estudos como um dos maiores problemas enfrentados por esta população ${ }^{29}$. Outrossim, o idioma é uma das diferenças culturais mais importantes e pode ser tornar uma das maiores barreiras na adaptação dos imigrantes. Essa habilidade está diretamente associada à adaptação sociocultural na medida que a fluência no idioma interfere na quantidade e qualidade da interação com os anfitriões e possibilita um decréscimo dos problemas cotidianos ${ }^{30}$.

Os resultados desta pesquisa também indicam que a principal estratégia de aculturação adotada pela maioria dos participantes é a separação, sendo que os relatos sugerem que todos os decasséguis e dois sojourners adotam essa estratégia. Esses resultados estão em consonância com os achados de outras pesquisas sobre a questão da separação social entre brasileiros e japoneses ${ }^{31}$. A adoção da estratégia de separação pode ser verificada através da visão negativa dos participantes sobre os japoneses, do pouco interesse e envolvimento com a cultura nipônica e da prevalência de uma identidade predominantemente brasileira, manifestada através de comportamentos, hábitos e envolvimento com as questões relacionadas ao Brasil. Adicionalmente, essa separação é reafirmada pelos possíveis conflitos existentes entre brasileiros e japoneses, especialmente refletida nas percepções de discriminações dos japoneses para com os estrangeiros, com mais frequência manifestadas pelos decasséguis. Entretanto, conforme descrito anteriormente, a integração tem sido apontada como a estratégia mais adequada para o contexto de aculturação por possibilitar maiores benefícios ao imigrante em várias esferas da vida. Ainda que a integração seja a estratégia mais adequada, existem alguns fatores que interferem na escolha, quando há,

\footnotetext{
${ }^{29}$ RESSTEL, op. cit.

${ }^{30}$ WARD, Colleen, MASGORET, Anne Marie. An integrative model of attitudes toward immigrants.

31 TSUDA, op. cit.
} 
da estratégia a ser adotada. Dentre esses fatores destaca-se a distância cultural entre os países em questão, a diversidade cultural na sociedade anfitriã, nível de educação, percepção da cultura de origem e da anfitriã, idioma, idade e sexo ${ }^{32}$. Diante do exposto, os resultados deste estudo parecem relacionar o uso da estratégia de separação pelos brasileiros a um padrão específico do contexto dos brasileiros no Japão caracterizado por uma grande distância cultural entre Brasil e Japão, predominância de um ambiente cultural homogêneo e também como uma reação a um padrão de segregação aos grupos etnicamente diferentes por parte da sociedade japonesa ${ }^{33}$.

Embora a maioria dos participantes indica adotar a separação como estratégia de aculturação, a maior parte defende que o interesse, conhecimento, respeito e engajamento na cultura japonesa são primordiais para que haja uma boa adaptação ao país. Tal constatação pode ser evidenciada nas definições de adaptação cultural, nas dificuldades, facilitadores e estratégias de enfrentamento relatados pelos participantes. Desta maneira, ainda que existam evidências de problemas relacionados à aceitação e interação com a cultura japonesa, o grande destaque atribuído à adoção de características culturais locais assinala para o papel da integração como importante forma de se relacionar culturalmente em situações de imigração. Esses resultados também estão relacionados ao uso de estratégias de enfrentamento mais ativas, também chamadas de focadas no problema ${ }^{34}$, como importante estratégia para a vida no Japão e para o fenômeno da aculturação.

Os achados deste estudo também enfatizam a importância dos vínculos sociais para o fenômeno da aculturação. A maioria dos participantes ressaltou fortemente a questão dos vínculos sociais em diversos momentos da entrevista que se estendem desde a opinião sobre os japoneses, o Brasil, a vida, as dificuldades, os facilitadores da vida no Japão até as estratégias de enfrentamento utilizadas. A questão dos vínculos sociais está diretamente relacionada ao conceito de suporte social. Embora haja discordâncias na maneira de se definir e operacionalizar o construto suporte social, parece ser um consenso entre os acadêmicos de que as relações próximas e profundas desempenham um papel essencial na vida dos humanos ${ }^{35}$ e estão associadas à redução do estresse e promoção de bem-estar físico e emocional em situações de encontros interculturai ${ }^{36}$. Desta maneira, os resultados desta pesquisa estão

${ }^{32} \mathrm{YU}$, Weihua, WANG, Shu. An investigation into the acculturation strategies of Chinese students in Germany.

33 TSUDA, op. cit.

${ }^{34}$ LAZARUS, Richard, FOLKMAN, Susan. Stress, appraisal, and coping.

${ }^{35}$ FEENEY, Brooke, COLLINS, Nancy. A New Look at Social Support: A Theoretical Perspective on Thriving Through Relationships.

${ }^{36}$ ONG, Andy, WARD, Colleen. The construction and validation of a social support measure for sojourners: The Index of Sojourner Social Support (ISSS) Scale. 
em consonância com os apontamentos da literatura sobre o papel importante desta variável para a adaptação cultural.

De modo geral, podem-se resumir as contribuições desta pesquisa em três pontos: teóricos, práticos e metodológicos. Do ponto de vista teórico, sugere-se que esta pesquisa ampliou a compreensão das formas de aculturação dos brasileiros ao Japão ao identificar variáveis psicológicas percebidas como importantes para a adaptação nesse país e investigou uma temática ainda pouco estudada no Brasil ou com populações de brasileiros no Japão sob o olhar da Psicologia Transcultural. Do ponto de vista prático, esta pesquisa visa encorajar políticas públicas integracionistas que sejam mais direcionadas e antenadas com as necessidades dos imigrantes brasileiros no Japão: como exemplo enfatiza-se a questão do ensino do idioma japonês e a união de esforços para a construção de um ambiente de suporte social à comunidade brasileira no país. Adicionalmente, sugere-se a criação de estratégias de intervenção psicológica voltadas para a questão da adaptação cultural dos brasileiros ao Japão. Do ponto de vista metodológico, este estudo permitiu explorar com profundidade a realidade de alguns representantes da comunidade brasileira no Japão e assim conhecer aspectos psicológicos pouco explorados na literatura através de um estudo qualitativo sem, contudo, ter a pretensão de generalizar para toda a população alvo. Esta pesquisa também permitiu compreender dois grupos diferentes de imigrantes, apontando características importantes deste processo para cada um. Como limitações, cita-se o número reduzido de participantes e a ausência de representantes da primeira e segunda geração de descendentes de japoneses. Outrossim, esta pesquisa utilizou apenas entrevistas como estratégias de coleta de dados, o que poderia ter favorecido respostas de desejabilidade social. Pesquisas futuras poderiam abranger as populações não contempladas neste estudo e outras técnicas de coleta de dados, diferentes da entrevista, que possibilitem diminuir os vieses do autorrelato.

\section{Referências bibliográficas}

ARENDS-TÓTH, Judit; VAN DE VIJVER, Fons Josephus Rachel. Issues in the conceptualization and assessment of acculturation. In BORNSTEIN, Marc H.; COTE, Linda R. (eds.). Acculturation and parent-child relationships: Measurement and development. Mahwah, NJ: Lawrence Erlbaum, 2006, p. 33-62.

BARDIN, Laurence. Análise de Conteúdo. Lisboa: Edições 70, 2004.

BERRY, John. Immigration, acculturation and adaptation. Applied Psychology: An international Review, v. 46, n. 1, 1997, p. 5-68.

FEENEY, Brooke; COLLINS, Nancy. A New Look at Social Support: A Theoretical Perspective on Thriving Through Relationships. Personality and Social Psychology Review, v. 19, n. 2, 2014, p. 1-35. 
ISHIKAWA, Eunice Akemi. A identidade étnica dos jovens brasileiros no Japão. Estudos japoneses, n. 36, 2016, p. 29-42. Disponível em: < http://www.revistas. usp.br/ej/article/view/127688/124714 > . Acesso em: 13.07.2017.

JAPAN STATISTICAL YEARBOOK 2017. Statistics Bureau. Ministry of Internal Affairs and Comunnications, Japan. 2017. Disponível em: <http://www.stat.go.jp/ english/data/nenkan/66nenkan/index.htm > . Acesso em: 18.05.2017.

KUO, Ben C. H. Collectivism and coping: Current theories, evidence, and measurements of collective coping. International Journal of Psychology, v. 48, n. 3, 2012, p. 374-388.

KUO, Ben; KWANTES, Catherine. Testing predictive models of positive and negative affect with psychosocial, acculturation, and coping variables in a multiethnic undergraduate sample. SpringerPlus, v. 3, n. 1, 2014, p. 119.

LAZARUS, Richard; FOLKMAN, Susan. Stress, appraisal, and coping. New York: Springer Publishing, 1984.

MÄHÖNEN, Tuuli Anna; JASINSKAJA-LAHTI, Inga. Acculturation expectations and experiences as predictors of ethnic migrants' psychological well-being. Journal of Cross-Cultural Psychology, v. 44, n. 5, 2013, p. 786-806.

MUSSO, Pasquale; INGUGLIAA, Cristiano; LO COCO, Alida. Acculturation Profiles and Perceived Discrimination: Associations with Psychosocial Well-being Among Tunisian Adolescents in Italy. Social Inquiry into Well-being, v. 1, n. 1, 2015, p. 76-90.

NGUYEN, Angela-Minhtu; BENET-MARTíNEZ, Verónica. Biculturalism and adjustment: A meta-analysis. Journal of Cross-Cultural Psychology, v. 44, n. 1, 2013, p. 122-159.

ONG, Andy; WARD, Colleen. The construction and validation of a social support measure for sojourners: The Index of Sojourner Social Support (ISSS) Scale. Journal of Cross-Cultural Psychology, v. 36, n. 6, 2005, p. 637-661.

REDFIELD, Robert; LINTON, Ralph; HERSKOVITS, Melville. Memorandum for the study of acculturation. American Anthropologist, v. 38, 1936, p. 149-152.

RESSTEL, Cizina Célia Fernandes Pereira. Desamparo psíquico nos filhos de Dekasseguis no retorno ao Brasil. Dissertação de Mestrado. Universidade Estadual Paulista, Assis, SP, 2014.

SAM, David; BERRY, John. The Cambridge Handbook of Acculturation Psychology. Cambridge, UK: Cambridge University Press, 2006.

SAM, David; BERRY, John. Acculturation: When Individuals and Groups of Different Cultural Backgrounds Meet. Perspectives on Psychological Science, v. 5, n. 4, 2010, p. 472-481.

SEARLE, Wendy; WARD, Colleen. The prediction of psychological and sociocultural adjustment during cross-cultural transitions. International Journal of Intercultural Relations, v. 14, n. 4, 1990, p. 449-464.

SUGUIURA, Marcos Hiroyuki. Relações entre a rede social e as migrações BrasilJapão. Dissertação de Mestrado. Instituto de Psicologia. Universidade de São Paulo, São Paulo, SP, 2009. 
TSUDA, Takeyuki. Migration and Alienation: Japanese-Brazilian Return Migrants and the Search for Homeland Abroad. The Center for Comparative Immigration Studies (CCIS), Working Paper, 24. University of California, San Diego, 2000. Disponível em: <http://ccis.ucsd.edu/publications/papers.html>. Acesso em: 24.09.2016.

WARD, Colleen; MASGORET, Anne Marie. An integrative model of attitudes toward immigrants. International Journal of Intercultural Relations, v. 30, n. 6, 2006, p. 671-682.

WILSON, Jessie; WARD, Colleen; FISCHER, Ronald. Beyond culture learning theory: What can personality tell us about cultural competence? Journal of CrossCultural psychology, v. 44, n. 6, 2013, p. 900-927.

YANO, Luciane Patrícia. Famílias brasileiras no Japão: migração transnacional, adaptação e estresse aculturativo. Porto Alegre: Poá Comunicação, 2013.

YU, Weihua; WANG, Shu. An investigation into the acculturation strategies of Chinese students in Germany. Intercultural Communication Studies, v. 20, n. 2, 2011, p. 190-210. Disponível em: <http://web.uri.edu/iaics/ files/15WeihuaYuShuWang.pdf > . Acesso em: 15.10.2016.

Recebido para a publicação em 04.08.2017

Aceito para publicação em 30.10.2017

Received for publication in August 04 ${ }^{\text {th }}, 2017$

Accepted for publication in October 30

ISSN impresso 1980-8585

ISSN eletrônico 2237-9843

http://dx.doi.org/10.1590/1980-85852503880005213 